\title{
Mathematical Model Quartic Curve Bezier of Modification Cubic Curve Bezier
}

\author{
Juhari \\ Mathematics Department, Universitas Islam Negeri Maulana Malik Ibrahim Malang \\ Email: juhari@uin-malang.ac.id
}

\begin{abstract}
The creative industries have become the government's attention for contributing to economic accretion. But due to the lack of artistic creativity and appeal, the evolution of the creative industries' craft section is not optimal. So that it was needed a variation of relief items to increase attractiveness. In general, an industrial object's design is still limited to the space geometry objects or a Bezier curve of degree two. Therefore, Bezier curves of degree are selected and modified it into a quartic Bezier forms and then applied to the design of industrial objects (glassware). The purpose of this research is to determine the formula of the quartic Bezier form of cubic Bezier modifications and to determine the rotary surface shape of quartic Bezier from cubic Bezier modifications. Then, from some form of the revolving surface of modified cubic Bezier, the glassware designs are generated. The results of this research are, first, the formula of the quartic Bezier result of Bezier cubic modifications. Second, the form of the revolving surface of modified cubic Bezier which is influenced by five control points $P_{0}, N P_{31}, N P_{32}, N P_{33}, P_{3}$ and parameter selection $\lambda_{31}, \lambda_{32}, \lambda_{33}$. For further research, it is expected to develop a modification of cubic Bezier into Bezier of degree- $n$
\end{abstract}

Keywords: cubic Bezier modification; quartic Bezier; Modeling

\section{INTRODUCTION}

Geometry is one of the mathematical sciences that discuss the shape, size, position of an object, both space and field objects. In its development, the geometry consists of space geometry and field geometry. The merger of both geometries can be utilized in object design. According to [1], the Bezier curve is a polynomial-based curve that is often utilized to design objects and form the surface of objects. The Bezier curve is an ideal standard to represent a more complex polynomial curve. Previous studies have covered the Bezier quadratic curve, which is utilized to design objects [2]. However, there is an issue of lack of curvature variation of curves and the design of objects confined to the geometry of a particular space. The applicability of the metric Bezier character curves and swivel on the lampshade model using the Maple 13 performed by Juhari [3]. In the study discussed the Bezier quadratic curve applied to the components of the lampshade design. The lamp hood is formed intact and joined continuously. However, there is no modification of the curve into the shape of a higher degree curve. So that the lack of variation of curvature curve and design is only limited to the geometry objects of certain space. Wahyudi [4] has conducted research on the design of industrial objects with rotating objects that are implemented for the design of vase, glassware, jug, or Knop. The drawback is that the swivel surface obtained in the study generally has a single and flat 
curved surface so that variations of the shape obtained are less varied. In addition, Roifah [5] has been conducting research on knop or handle modelization using the merger of tube objects, irregular hexagons prisms, and rotary surfaces. The excess is the modification of the tube blanket curve using the quartic curve of Hermit and Bezier, thus producing a more convenient and versatile Knop model creation. The drawback is that a knop fabrication is only done on the geometric objects of a tube and a rectangular prism. In addition, the relief knop offered should be modified again on the rotating surface of the curve. Arinda [6] has conducted research on the construction of vases of flowers through the merger of several geometric objects of space. The excess is to obtain a variance form of flower vase through the construction of a space-building such as a prism, pyramid, or a tube. The disadvantage is the manufacture of flower vase simply by constructing the building of the prism Chamber, Pyramid, or the jar of tubes.

In connection with these issues, the development of the Bezier quadratic curve is needed to higher degrees with the addition of a curve modification to provide a variation of curvature of the curve that can be utilized for the modelization of Industrial objects (glassware). In this study, further discussed equations and Bezier quartic swivel surfaces of the Bezier cubic curve modified on the design of the glassware.

\section{METHODS}

The steps used in determining Bezier's quartic curve formula are, first to create a Hermit quartic matrix, second to determine the new polygon control points $\Omega=$ $\left[P_{0}, N P_{31}, N P_{32}, N P_{33}, P_{3}\right]$, third, making Bezier's quartic equation from the modified Bezier cubic curve, finally making Bezier's quartic rotational surface shapes from Bezier's cubic modification.

In making these surface forms, several steps are required as follows:

a. Determine point data.

b. Construct a cubic Bezier curve resulting from cubic modification using point data to provide curvature.

c. Rotate or interpolate Bezier curves.

d. Bezier quartic curve simulation with point data determined using Maple 13.

\section{RESULTS AND DISCUSSION}

\section{Hermit Cubic Curve}

According to [7], the Hermit curve was discovered by a French mathematician named Charles Hermit in 1822-1901. The Hermit cubic curve segment is an interpolated curve of the two control points $P_{0}$ dan $P_{1}$ where this curve requires the well-knew tangent vectors of the U-parameter variables of the control points that are $P_{0}^{u}$ dan $P_{1}^{u}$. The algebraic form of a parametric cubic curve $P(u)$ is for supposing by following three polynomials:

$$
\begin{aligned}
& x(u)=a_{x}+b_{x} u+c_{x} u^{2}+d_{x} u^{3} \\
& y(u)=a_{y}+b_{y} u+c_{x} u^{2}+d_{x} u^{3} \\
& z(u)=a_{z}+b_{z} u+c_{z} u^{2}+d_{x} u^{3}
\end{aligned}
$$

Where $a, b, c$, and $d$ are the coefficients that follow the $x, y$, and $z$ equations with $u$ parameter that are delimited in intervals $0 \leq u \leq 1$ or $u \in[0,1]$. Next of the shape curve (1), is written in the parametric form: 


$$
P(u)=a+b u+c u^{2}+d u^{3}
$$

Then based on equations (2) specified the following conditions:

$$
\begin{aligned}
& P(0)=a \\
& P(1)=a+b+c+d \\
& P^{u}(0)=b \\
& P^{u}(1)=b+2 c+3 d
\end{aligned}
$$

If the system equation (3) is resolved, it is acquired Hermit matrix and obtained vectorvectors $a, b$, c, and $d$ as follows:

$$
\begin{aligned}
& a=P_{0} \\
& b=P_{0}^{u} \\
& c=-3 P_{0}+3 P_{1}-2 P_{0}^{u}-P_{1}^{u} \\
& d=2 P_{0}-2 P_{1}+P_{0}^{u}+P_{1}^{u}
\end{aligned}
$$

Equations (4) substituted into equations (2) hence the acquired cubic curve equation of Hermit.

$$
P(u)=H_{1}(u) P_{0}+H_{2}(u) P_{1}+H_{3}(u) P_{0}^{\prime}+H_{4}(u) P_{1}^{\prime}
$$

With

$$
\begin{aligned}
& H_{1}(u)=\left(1-3 u^{2}+2 u^{3}\right) \\
& H_{2}(u)=\left(3 u^{2}-2 u^{3}\right) \\
& H_{3}(u)=\left(u-2 u^{2}+u^{3}\right) \\
& H_{4}(u)=\left(-2 u^{2}+u^{3}\right)
\end{aligned}
$$

The shape of the equation (5) is called the presentation of curves in the geometric form, and the $P_{0}, P_{1}, P_{0}^{u}$, and $P_{1}^{u}$ are called geometric by. While the functions of $H_{1}(u), H_{2}(u), H_{3}(u)$ and $H_{4}(u)$ in equations (6) are called the base of Hermit, and its curve is called the Hermit curves [8].

\section{Bezier Cubic Curve}

The Bezier curve is a polynomial curve consisting of multiple sets of control points. The interpolated point of the curve is the first and last point, while the second to point $P_{n-1}$ is the approximate tangent and magnitude used to control the curvature of the curve. Bezier polynomial curves $\mathrm{n}$ expressed in the parametric form are:

$$
C(u)=\sum_{i=0}^{n} P_{i} B_{i}^{n}(u), u \in[0,1]
$$

where its function base is

$$
\begin{aligned}
B_{i, n}(u) & =\left(\begin{array}{c}
n \\
i
\end{array}\right) u^{i}(1-u)^{n-1} \\
\left(\begin{array}{c}
n \\
i
\end{array}\right) & =\frac{n !}{i !(n-i) !}
\end{aligned}
$$

In such equations, the points of the $P_{i}$ are called the geometric coefficient or $C(u)$ curve control point. These points are of real value. For 4 dots and $n=3$ :

$$
\begin{aligned}
& B_{0,3}=(1-u)^{3} \\
& B_{1,3}=3 u(1-u)^{2} \\
& B_{2,3}=3 u^{2}(1-u)
\end{aligned}
$$




$$
B_{3,3}=u^{3}
$$

Thus obtained a Bezier cubic curve with the $u$ parameter as follows:

$$
C_{3}(u)=(1-u)^{3} P_{0}+3(1-u)^{2} u P_{1}+3(1-u) u^{2} P_{2}+u^{3} P_{3}
$$

\section{Hermit Quartic Matrix}

Suppose taken parametric quartic curve with $P(u)$ expressed in the form of algebraic:

$$
\begin{aligned}
& x(u)=a_{x}+b_{x} u+c_{x} u^{2}+d_{x} u^{3}+e_{x} u^{4} \\
& y(u)=a_{y}+b_{y} u+c_{x} u^{2}+d_{x} u^{3}+e_{y} u^{4} \\
& z(u)=a_{z}+b_{z} u+c_{z} u^{2}+d_{z} u^{3}+e_{z} u^{4}
\end{aligned}
$$

Where $a, b, c, d$, and $e$ are the coefficients that follow the $x, y$, and $z$ equations with the $u$ parameter delimited in intervals of $0 \leq u \leq 1$ or $u \in[0,1]$. $u$ value restriction is intended to keep the curve segment awake Limited and easy to control.

Based on the equation (1) it can be written into a parametric form so that it becomes:

$$
P(u)=a+b u+c u^{2}+d u^{3}+e u^{4}
$$

In which coefficients $a, b, c, d$ and $e$ in Equation $\mathrm{P}(\mathrm{u})$ are vectors that have three components, such as $a=\left[a_{x}, a_{y}, a_{z}\right]$. Then in getting the first derivative of $P(u)$ is:

The second derivative of $P(u)$ is:

$$
P^{u}(u)=b+2 c u+3 d u^{2}+4 e u^{3}
$$

Then set some of the following conditions:

$$
P^{u u}(u)=2 c+6 d u+12 e u^{2}
$$

$$
\begin{array}{ll}
P(u=0) & =P_{0}=a \\
P(u=1) & =P_{1}=a+b+c+d+e \\
P^{u}(u=0) & =P_{0}^{u}=b \\
P^{u}(u=1) & =P_{1}^{u}=b+2 c+3 d+4 e \\
P^{u u}(=0) & =P_{0}^{u u}=2 c
\end{array}
$$

Hence the modification of Hermit is derived:

$$
\mathrm{M}_{\mathrm{MH}}=\left[\begin{array}{ccccc}
1 & 0 & 0 & 0 & 0 \\
0 & 0 & 1 & 0 & 0 \\
0 & 0 & 0 & 0 & \frac{1}{2} \\
-4 & 4 & -3 & -1 & -1 \\
3 & -3 & 2 & 1 & \frac{1}{2}
\end{array}\right]
$$

\section{Quartic Bezier Curve of Modification Cubic Bezier Curve}

Suppose given the new Bezier polygon control dots $\Omega=\left[P_{0}, N P_{31}, N P_{32}, N P_{33}, P_{3}\right]$, then the control point between $N P_{31}, N P_{32}, N P_{33}$ is defined as the following:

With $0 \leq \lambda_{31}, \lambda_{32}, \lambda_{33} \leq 1$.

$$
\begin{aligned}
& N P_{31}=\lambda_{31} P_{1}+\left(1-\lambda_{31}\right) P_{0} \\
& N P_{32}=\lambda_{32} P_{2}+\left(1-\lambda_{32}\right) P_{1} \\
& N P_{33}=\lambda_{33} P_{3}+\left(1-\lambda_{33}\right) P_{2}
\end{aligned}
$$

Furthermore, the new control points defined $P_{0}, N P_{31}, N P_{32}, N P_{33}$ and $P_{3}$ to create a Bezier quartic equation of the Bezier cubic modification as follows, $B(0)=P_{0}$ 


$$
\begin{aligned}
& B(1)=P_{3} \\
& B^{\prime}(0)=4\left(N P_{31}-P_{0}\right) \\
& B^{\prime}(1)=4\left(P_{3}-N P_{33}\right) \\
& B^{\prime \prime}(0)=12\left(P_{0}-2 N P_{31}+N P_{32}\right)
\end{aligned}
$$

Thus modification of the Bezier cubic curve into the Bezier quartic form,

$$
\begin{aligned}
B_{4}(u)= & {\left[\left(1-4 u+6 u^{2}-4 u^{3}+u^{4}\right) P_{0}+\left(4 u+12 u^{2}+12 u^{3}\right.\right.} \\
& \left.-4 u^{4}\right) N P_{31} \\
+ & \left.\left(6 u^{2}-12 u^{3}+6 u^{4}\right) N P_{32}+\left(4 u^{3}-4 u^{4}\right) N P_{33}+u^{4} P_{3}\right]
\end{aligned}
$$

With $0 \leq u \leq 1 \ldots$ In Figure 3.1 is shown a Bezier cubic curve difference using equations (2.13) and the Bezier quartic curve of a Bezier cubic modification using equations (3.4) with point $P_{0}=(9,0,3), P_{1}=(4,0,5), P_{2}=(4,0,9)$, and $P_{3}=(9,0,12)$ with the parameter value $\lambda_{31}=0.2, \lambda_{32}=0.6$, and $\lambda_{33}=0.9$.

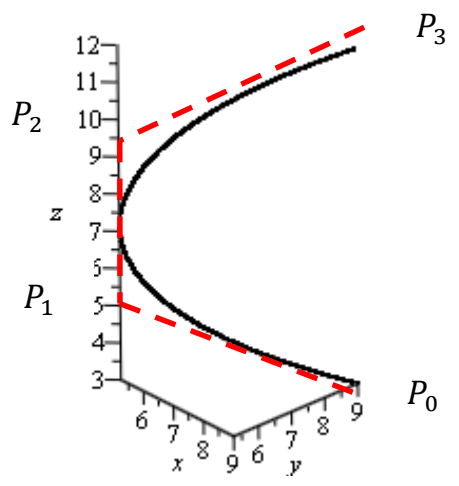

Bezier Cubic Curve

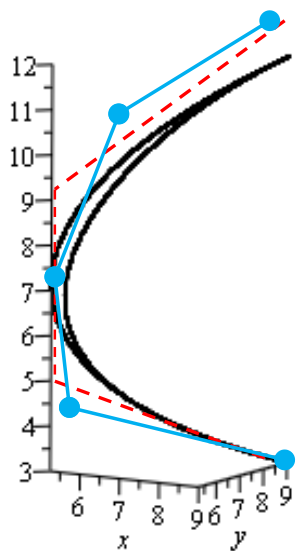

Bezier quartic curve result cubic modification

Figure 1. Example Cubic Bezier Curve and Quartic Bezier Curve

\section{Quartic Bezier Surface from Modified Cubic Bezier}

Bezier Quartic Shapes modified the Bezier cubic curve is dependent on the determination of the $P_{0}, P_{1}, P_{2}$ and $P_{3}$ control points. Because of the case of point modification, a new control point or a modification point in $N P_{31}, N P_{32}$, and $N P_{33}$ in the equation (3.4). The point determination is used to produce a smoother curve. Figure 1 is an example of a Bezier quartic rotary surface of a Bezier cubic modification with some selection of $P_{0}, P_{1}, P_{2}$, and $P_{3}$ control points and a parameter of $\lambda_{31}, \lambda_{32}, \lambda_{33}$ on the different modifications of $N P_{31}, N P_{32}$, and $N P_{33}$.

Bezier Cubic Rotating surface

$$
\begin{gathered}
P_{0}=(11,0,0), P_{1}=(10,0,3) \\
P_{2}=(20,0,4), \text { dan } P_{3}=(17.5,0,10)
\end{gathered}
$$

Bezier quartic Rotary Surface modified Bezier cubic curve.

$$
\begin{gathered}
P_{0}=(11,0,0), P_{1}=(10,0,3) \\
P_{2}=(20,0,4), \operatorname{dan} P_{3}=(17.5,0,10) \\
\lambda_{31}=0.75, \lambda_{27}=1, \lambda_{22}=0
\end{gathered}
$$
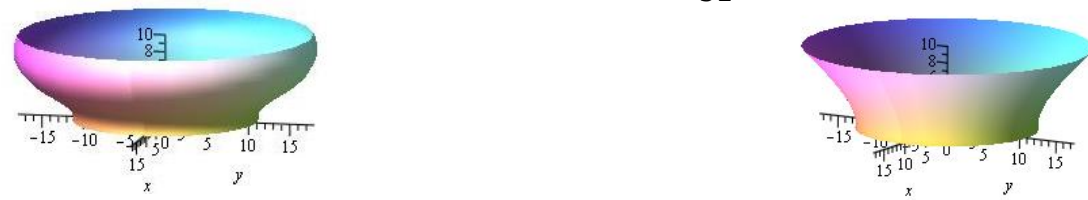
$P_{0}=(3.5,0,0), P_{1}=(0,0,2)$
$P_{2}=(4,0,4), \operatorname{dan} P_{3}=(3.5,0,12)$
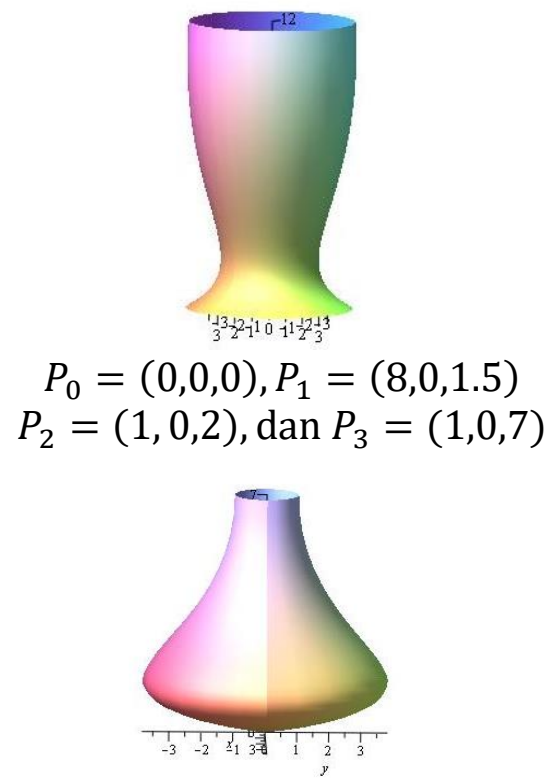
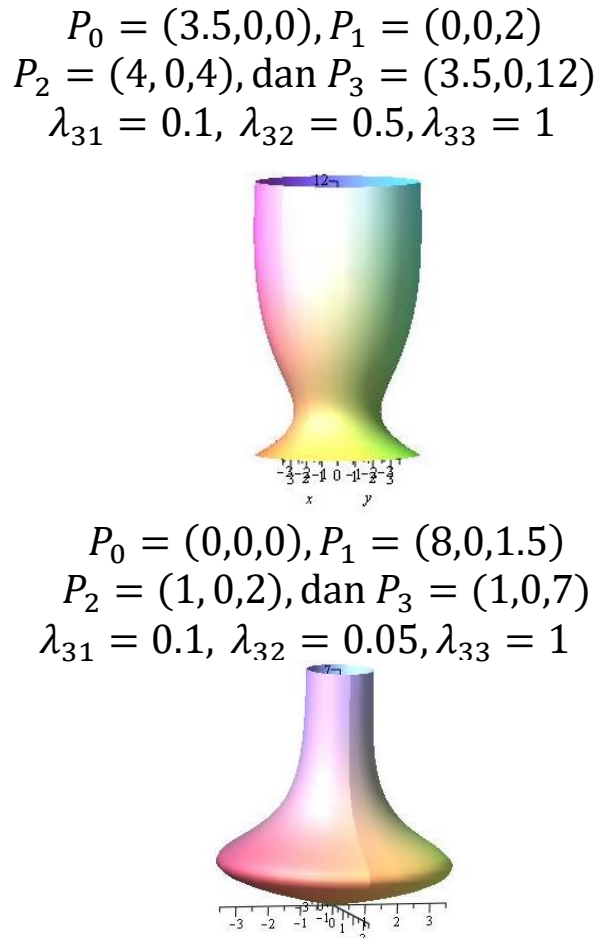

Figure 2. Cubic Bezier Surfaces and Modifications

Subsequently, some Bezier quartic swivel surfaces from the Bezier cubic modification results can be converted to model industrial objects (glassware) such as flower vase, teplik lamps, marble chairs, and other glassware. Figure 2 illustrates the design example of glassware using some form of Bezier quartic of the Bezier cubic curve modification.

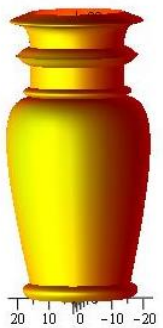

Jar

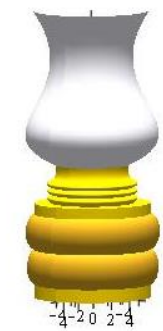

Teplik Lamp

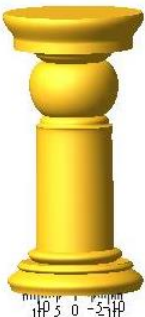

Marble Chairs

Figure 3. Example of design of glassware using a Bezier quartic of a Bezier cubic modification

\section{CONCLUSIONS}

The Bezier quartic equation results from the Bezier cubic modification obtained from the Hermit modification matrix and the determination of a new polygon control point. The Bezier cubic modified form of Bezier modification has 5 control points: $P_{0}, N P_{31}, N P_{32}, N P_{33}, P_{3}$. Forms of Scartic Bezier turndown surface of Bezier cubic modification is influenced by the control point values of $P_{0}, P 1, P_{2}, P_{3}$, and selection of parameters of $\lambda_{31}, \lambda_{32}, \lambda_{33}$ values in new control point data $N P_{31}, N P_{32}$ and $N P_{33}$. 


\section{REFERENCES}

[1] E. Mortenson, Mathematics for Computer Grapichs Applications, New York: Industrial Press, Inc, 1999.

[2] A. C. P. M. D. Kusno, "Modelisasi Benda Onyx dan Marmer Melalui Penggabungan dan Pemilihan Parameter Pengubah Bentuk Permukaan Putar Bezier," Jurnal Ilmu Dasar, vol. 8, no. 2, pp. 175-185, 2007.

[3] E. O. Juhari, "Penerapan Kurva Bezier Karakter Simetrik dan Putar pada Model Kap Lampu Duduk Menggunakan MAPLE," CAUCHY: Jurnal Matematika Murni dan Aplikasi, vol. 4, no. 1, pp. 28-34, 2015.

[4] Wahyudi, "Perancangan Objek-Objek Industri dengan Benda Permukaan Putar," Universitas Jember, Jember, 2001.

[5] Roifah, "Modelisasi Knop Melalui Penggabungan Benda Dasar Hasil Deformasi Tabung, Prisma Segienam Beraturan, dan Permukaan Putar," Universitas Jember, Jember, 2013.

[6] Arinda, "Konstruksi Vas Bunga Melalui Penggabungan Beberapa Benda Geometri Ruang," Universitas Jember, Jember, 2007.

[7] E. Mortenson, Geometric Modelling, New York: Willey Komputer Publishing, 1996.

[8] Kusno, Geometri Rancang Bangun Studi Surfas Putar Transformasi Titik Dan Proyeksi, Jember: Jurusan Matematika Fakultas MIPA Universitas Jember, 2003. 